\title{
A dinâmica das relações familiares de moradores de rua usuários de crack
}

\author{
The family relationships dynamics of homeless people-crack users
}

Jaime Alonso Caravaca-Morera', Maria Itayra Padilha²

RESUMO Pesquisa qualitativa com abordagem sócio-histórica que objetivou analisar como se constitui a subjetividade dos indivíduos no contexto da relação família, rua e crack. Os participantes foram 15 moradores de rua da cidade de Florianópolis (SC). A coleta de dados foi realizada de fevereiro a abril de 2013. Os dados foram analisados segundo a Análise de Conteúdo de Bardin. Os resultados destacam que a ausência de regras, limites, comunicação e afeto no núcleo familiar, assim como a violência e o uso/abuso de drogas, foram fatores que colaboraram com o consumo do crack e a moradia de rua. Conclui-se que as relações familiares fragilizadas são um dos fatores de risco corresponsáveis no consumo do crack e a moradia na rua.

PALAVRAS-CHAVE Relações familiares; Cocaína crack; Moradores de rua; Histórias de vida.

ABSTRACT A qualitative research with a socio-historical approach aimed at analyzing the constitution of subjectivity in the context of family relationships of homeless-crack users. The study subjects were 15 homeless people of the city of Florianópolis (SC). Data collection was conducted from February to April 2013. The data were analyzed using the Content Analysis of Bardin. The results highlighted that the absence of rules, boundaries, communication and affection in the household, as well as the presence of violence and drug abuse, were factors that cooperated with the onset of crack use and subsequently led to adopting the streets as a home. It was concluded that weakened family relationships share responsibility for crack consumption and the homeless scenario.

KEYWORDS Family relations; Crack cocaine; Homeless; Life Stories.

1 Universidad de Costa Rica (UCR) - San José, Costa Rica. Universidade Federal de Santa Catarina (UFSC)

- Florianópolis (SC), Brasil. jacamorera@hotmail.com

2 Universidade Federal de Santa Catarina

(UFSC), Departamento

de Enfermagem -

Florianópolis (SC), Brasil.

padilha@nfr.ufsc.br 


\section{Introdução}

As discussões atuais sobre os fenômenos pessoais e sociais envolvidos no consumo de crack e na moradia de rua têm gerado uma gama de preocupações nos diferentes contextos sociais. Existem várias explicações que poderiam auxiliar na compreensão dessa temática a depender da corrente teórica ou paradigma epistêmico utilizado. Por isso, diversas inquietações surgem no meio acadêmico em pesquisas que abordam esse tema, evidenciando a necessidade de apreender, compreender, analisar, refletir e investigar a estrutura familiar, sendo esta uma instituição denominada como o núcleo da sociedade contemporânea que tem alguma (ou muita) responsabilidade no problema das dependências químicas. Ressalta-se que os problemas das toxicomanias em geral, e principalmente a do crack, devem ser analisados como situações singulares vinculadas a um contexto social, econômico, cultural e político específico de cada realidade.

A família é uma instituição complexa que congrega trajetórias individuais e que se expressa em arranjos diversificados e em espaços únicos ligados diretamente às transformações da sociedade. Esse sistema plural se reveste de diversas definições e controvérsias, e há relevância no que se refere ao processo de crescimento e desenvolvimento de seus membros, sendo que nela acontece o primeiro processo de socialização (ELSEN; MARCON; SANTOS, 2002).

O dinamismo das diversas abordagens e paradigmas sociais destacam que a ausência de um acordo interno com regras claras intrafamiliares se converte em uma das principais variáveis facilitadoras no aparecimento de quadros de inclinação ao uso de qualquer substância psicoativa.

Autores, como Freitas (2002) e Alarcão (2006), revelam duas condições necessárias, entre outras, que podem levar uma pessoa a se tornar usuária abusiva de uma substância psicoativa: a) a aproximação e o acesso que esta tem com a droga, b) a relação/interpretação com a transgressão das regras familiares. Contudo, é importante destacar que existem várias explicações que abordam esse fenômeno a depender da corrente teórica ou paradigma epistémico utilizado. Entretanto, questiona-se no presente estudo: o que ocorre quando essas regras/ normativas familiares nunca estiveram presentes? Será que uma criança, jovem ou adulto estaria transgredindo uma regra que desconhece?

É reconhecido que as normas fazem parte da formação do ser humano e do cidadão, contudo, sabe-se que nem todas as famílias contam com uma concepção de normas e limites que são transmitidos aos filhos, relações estas que indicam o que se deve e o que não se deve fazer. Fato inverso também acontece: uma família que se relaciona com normas claras pode também contribuir para o que aqui denomina-se sedução com a droga.

É importante mencionar que quando as funções paternas ou maternas não são exercidas de uma forma firme e amorosa, os interditos e as proibições dificilmente serão respeitadas, e os ideais que poderiam servir como suporte ético na tomada de decisões futuras poderão ser desvirtuados e invisibilizados (BUENO ET AL., 2012).

Por outra parte, considerando que os seres humanos são integrais e integrados, qualquer alteração psicossocial produz uma resposta imediata no corpo, o qual está condicionado à busca da homeostasia. Esse equilíbrio homeostático poderá ser alterado não só por desordens fisiológicas como também por notória participação de fatores externos, tais como as relações familiares conflituosas, estresse, pobreza, violência estrutural, consumo de drogas, entre outros fenômenos, podendo produzir modificações comportamentais e psíquicas importantes (CASSELL, 2003).

Conhecer como são as relações familiares que modificam essas capacidades psíquicas 
de expressão de sentimentos, que estão envolvidas nas histórias de vida das pessoas, é importante para evidenciar que existem outras variáveis pouco investigadas - além das variáveis pessoais, econômicas, culturais e políticas - que incitam (ou facilitam) o processo de consumo de crack e a moradia na rua. Diante das anteriores inquietações, este estudo visa analisar como se constitui a subjetividade dos indivíduos no contexto da relação família, rua e crack.

\section{Percurso metodológico}

Este estudo insere-se nos pressupostos metodológicos da pesquisa qualitativa, que trabalha com o universo de significados, razões, justificativas, aspirações, crenças, valores e atitudes que colaboram com a compreensão das relações existentes em um fenômeno humano.

É uma pesquisa com abordagem sóciohistórica que utilizou as histórias de vida como técnica para coletar os dados. A escolha dessa técnica justificou-se devido ao entendimento de que a forma como uma pessoa age na atualidade é produto de uma série de acontecimentos ocorridos no passado, e isso reflete a ideia de que o hoje é somente uma consequência impregnada das referências que abrangem as perspectivas do mundo de ontem.

Os sujeitos do estudo foram 15 usuários de crack, sendo 11 do gênero masculino e 4 do gênero feminino, na faixa etária compreendida entre 18 e 35 anos, oriundos principalmente dos três estados do sul do Brasil: Santa Catarina, Paraná e Rio Grande do Sul. $\mathrm{O}$ número de sujeitos do gênero feminino foi menor devido ao fato de que as mulheres apresentaram mais receio de compartilhar suas histórias de vida e negaram sua participação neste estudo.

Os critérios de inclusão adotados foram: ser maior de 18 anos, ser/estar morador de rua de Florianópolis há pelo menos 2 anos, ser usuário de crack. O período estabelecido de residência nas ruas do município possibilitou uma visão mais ampla sobre os significados, adversidades e conhecimento das situações vivenciadas no seu cotidiano.

A coleta de dados ocorreu nas ruas de Florianópolis, capital do estado de Santa Catarina, Brasil; sendo este o local de moradia dos sujeitos pesquisados. Entre os lugares selecionados para a realização da coleta das informações, encontraram-se os locais conhecidos como fumódromos, ou seja, lugares onde os moradores de rua e outros consumidores se reúnem para fazer uso de drogas fumadas na região central da cidade.

Para a realização das entrevistas, foi elaborado um roteiro com perguntas sobre a história de vida completa e outras experiências familiares pessoais, as quais foram gravadas e transcritas na íntegra. Essa coleta de dados aconteceu no período compreendido entre fevereiro e abril do ano 2013.

Após os esclarecimentos referentes ao estudo, à metodologia a ser utilizada e à forma de participação, os sujeitos assinaram o Termo de Consentimento Livre e Esclarecido (TCLE), assim como a Carta de Cessão da Entrevista (esses documentos foram lidos em voz alta e clara pelo pesquisador principal, todos os participantes foram encorajados a esclarecer dúvidas que porventura surgiram durante essa leitura e, ao final, em caso de positividade para a participação nesta pesquisa, pediu-se que eles fossem assinados). Foram respeitados os princípios de ética, sigilo, confidencialidade e privacidade durante todos os momentos da entrevista, os quais estiveram em consonância com a Resolução CNS n. ${ }^{\circ}$ 466, de 12 de dezembro de 2012 do Conselho Nacional de Saúde (CNS).

O estudo foi aprovado pelo Comitê de Ética em Pesquisa com Seres Humanos da Universidade Federal de Santa Catarina, diante a Resolução n. ${ }^{0}$ 202.673, assinada em 22 de fevereiro de 2013. A coleta das informações foi interrompida a partir do 
momento que ocorreu a saturação destas, dado que nenhum novo elemento ampliou o conhecimento do objeto que estava sendo investigado.

Os dados foram analisados segundo a técnica de Análise de Conteúdo de Bardin (2011), seguindo as etapas de coleta e preparação das informações; unitarização do conteúdo em unidades; classificação das unidades em categorias; descrição e interpretação. A partir disso, emergiram duas categorias assim elencadas: 'Lar doce lar? O meu era feito de fel' e 'A violência como parte do meu cotidiano familiar'. Essas categorias demonstraram a forte influência que a família também exerceu nos sujeitos para iniciarem o consumo de crack e, posteriormente, escolher a rua como seu lar.

\section{Resultados e discussão}

A experiência subjetiva obtida das descrições entrelaçadas nas histórias de vida dos 15 moradores de rua que participaram do estudo permitiu perceber que existem fatores compartilhados e em comum entre cada um deles, que favoreceram a aproximação, a inserção e a convivência com o consumo de drogas; e os efeitos deste consumo os seduziu, direcionando-os ao uso/abuso do crack. Posteriormente, eles adotaram as ruas como seus lares (contudo, é importante esclarecer que, independentemente de se interpretar como um fato linear, esta afirmação é um dado surgido na pesquisa).

Todos os sujeitos da pesquisa apresentaram um histórico de consumo de drogas semelhante, tendo início na infância com drogas lícitas, como o cigarro e o álcool; passando por drogas consideradas mais nobres, como o lança perfume, a cola de sapateiro, os cogumelos e as anfetaminas; seguido pelo consumo de outras drogas, como a maconha, LSD, cocaína e crack. Os 15 participantes compartilharam o denominador comum de que o crack foi a causa pela qual decidiram iniciar sua vida como moradores de rua.

\section{Lar doce lar? 0 meu era feito de fel}

Esta categoria foi composta por uma série de microunidades complexas que abordam de maneira detalhada e minuciosa a composição e condutas que as famílias dos sujeitos apresentaram durante a infância e a adolescência deles.

A família é o primeiro e o mais intenso agente de socialização e deve ser assumida como uma unidade de cuidado, transmissora de valores, suporte emocional e criadora de estratégias de promoção de saúde para os seus membros. Sendo assim, surge a ideia de que esse núcleo familiar deveria contar com algumas condições para colaborar com o afastamento dos seus membros de condutas prejudicais, como os vícios e adicções.

Nesse contexto, quando existe um filho consumidor de droga, ele é reconhecido por alguns autores como o indivíduo eleito para representar a falência do exercício parental. Esse membro é quem carrega claramente autoculpas, estigmas, remorsos e dores, causando múltiplos questionamentos sobre o porquê de eles/elas realizarem atos considerados fora da norma, como o consumo de drogas (CASSEL, 2002; ELSEN; MARCON; SILVA, 2002). Esta afirmação é corroborada nos depoimentos a seguir:

Eu sempre fui o peste da minha família, na verdade desde criança comecei a ver que eu era o filho mais bagunceiro, talvez eu nem queria ser assim, mas meus pais nem ligavam para mim, eles ficavam na deles, fazendo as coisas deles e eu ficava na minha bagunça. Eu não tive uma família perfeita, até porque todos eram viciados lá, mas eu acho que ainda assim eu era a ovelha negra da família. 
(Morador de rua 1).

Eu nunca prestei, desde criança minha mãe sempre falava que eu era um ninguém [...] ela realmente me odiava, não gostava de mim, ela e o namorado dela na época diziam que eu não valia nada, que eu só cheguei na vida deles para atrapalhar [...] eu na época não dava muita bola para isso, mas hoje em dia em acho que eles estavam certos eu sou um ninguém. (Morador de rua 2).

As impressões expostas acima evidenciam sentimentos de baixa autoestima, conflitos não elaborados e autopercepções pejorativas que, segundo Bursztyn (2000), poderiam ter surgido na infância e na adolescência, produto das dinâmicas familiares fragilizadas ou mudanças no âmbito psicológico, emocional e físico que os moradores de rua sofreram. Por conseguinte, considera-se que alguns dos jovens que se encontram nos primeiros ciclos vitais que não possuem uma estrutura psicoemocional firme, sendo esta reforçada pelos valores familiares positivos, representam ser um grupo de alto risco quanto ao uso de drogas.

Com base no que foi exposto acima, é possível sugerir que a maioria de pais de consumidores ao se perguntarem por que seu filho é usuário de uma droga tão devastadora como o crack não percebem que dentro da resposta se inclui uma corresponsabilidade parental.

As drogas nas histórias de vida dos entrevistados foram percebidas como a solução para preencher ou satisfazer as ausências paternas. Para ilustrar essa ideia, pode-se visualizar como alguns dos indivíduos significam de forma tão explícita sua experiência.

Eu comecei a usar drogas quando tinha 11 anos, porque vi no meu pai um espelho, ele sempre foi meu herói, embora ele não fosse a melhor pessoa do mundo, eu queria ser como ele, não sei por que, porque na verdade ele vivia bêbado [...] no início quando comecei fumar e beber cachaça eu vi que essas drogas tiravam meus sentimentos, tirava a dor da ausência da minha mãe, me davam forças para seguir. Quando era criancinha, e bebia, não sentia nada, não pensava, não sofria. A droga era um negócio que ia tomando conta do meu coração, da minha mente, do meu corpo, mas nunca chegou a preencher o vazio da perda da minha mãe. (Morador de rua 3).

Percebe-se que, inicialmente, as drogas eram utilizadas como uma forma de obter forças para suportar as dores emocionais durante alguns momentos. Essas afirmações vão ao encontro do pensamento de Eduardo Kalina et al. (1999), o qual expressa que a droga é utilizada como refúgio diante da frustração, fazendo uma analogia com o personagem de desenhos animados Popeye, que comia espinafre para ficar mais forte e enfrentava os problemas cotidianos (um fraco comia espinafre para ficar forte e enfrentar as adversidades momentaneamente), porém os participantes não percebiam que esse alívio era fugaz e acarretava ainda mais problemas.

É importante reconhecer que a adicção ao crack é o resultado da somatória de múltiplos fatores, que convergiram nas histórias de vida dos sujeitos da pesquisa. Nas relações familiares dos sujeitos pesquisados, encontraram-se sentimentos, como a falta de amor, carinho e abandono, conforme foi expresso por alguns dos sujeitos,

Comecei usar crack porque sempre sentia uma tristeza profunda, sem ninguém ao meu lado, vivia num lugar sem saídas, sem esperanças [...] não tinha ninguém com quem contar, minha mãe nunca me amou, meu pai ficava fora de casa vadiando com várias muIheres ao mesmo tempo, eu senti a falta do que as pessoas chamam de amor. (Morador de rua 4).

Desde que usei o crack aos 12 anos, minha vida virou uma mistura de tristezas, saudades, emoções e medos. A principal coisa que 
me fez usar essa bosta foi minha família, se eu tivesse tido uma família legal, que se preocupasse comigo, talvez eu nem estaria aqui contando essa história para você [...] mas minha vida foi uma merda, nunca ninguém me ajudou, ninguém me guiou, todos me odiavam. (Morador de rua 5).

Essas expressões mostram mensagens que clarificam o que está implícito no consumo de drogas. Nesse contexto, ele se apresentou como um grito de desespero, denunciando a ausência de amor parental e denotando a carência de ferramentas para lidar com a tristeza, incompreensão e frustração. Esse conjunto de sentimentos vivenciados desde as etapas mais precoces da vida conduziram o indivíduo a uma intolerância do seu cotidiano. Essa vida quase insuportável no seu mundo subjetivo era aliviada somente pelo anestésico que o crack fornecia:

O crack para mim foi o melhor anestésico do mundo, ele desde sempre acalmou as minhas dores de uma forma superficial, é obvio, mas acalma [...] Eu precisava na época (16 anos) de esquecer o sofrimento imundo que tinha no meu coração pela perda do meu irmão nas mãos do tráfico. (Morador de rua 6).

Observou-se, ainda, que o efeito esperado ao consumir qualquer droga é o de provocar um refúgio anestésico e amnésico capaz de aliviar as dificuldades vivenciadas, as dores e as angústias naquele momento. De forma geral, os entrevistados iniciaram o uso das drogas lícitas em suas casas durante a infância, principalmente consumindo bebidas alcoólicas e cigarros. Tais comportamentos foram estimulados pelos pais e irmãos mais velhos, que percebiam nesse tipo de conduta uma diversão e se tornaram parte da elaboração de uma justificativa no inconsciente da criança que respaldava esse consumo, haja vista que este uso era aceito pelos familiares:
Geralmente quando meu pai estava em casa a gente sempre ficava muito junto [...] Então ele falava, pega um cigarro para mim [...] Eu falava: 'Deixa eu acender, deixa eu acender'. E aí ele respondia: 'Vai acende' [...] Daí a minha mãe via e dava uma risadinha, ela gostava que eu acabasse com o cigarro antes de entregá-lo pro meu pai [...] Adorava fumar nessa época (9 anos), mas eu não entendia o que aquilo podia ocasionar, eu não sabia que aquilo iria acabar com minha vida e me trazer para morar aqui nesta lixeira. (Morador de rua 7 ).

Verifica-se, assim, como o consumo de drogas era banalizado pelos pais, o que produzia, de certa forma, um desgaste nos laços que uniam essas famílias, gerando concomitantemente uma patologia que danificava diretamente as pessoas e as relações familiares, confirmando que as adicções são uma sintomatologia que abrange os campos do individual e do coletivo (SOARES ET AL., 2009).

É comum afirmar que as dependências químicas são patologias percebidas de modo individual, pois existem elementos pessoais que levam ao consumo, provocando um círculo vicioso em que, posteriormente, esse consumo irá trazer consequências na saúde física, mental e emocional. No contexto desta pesquisa, reafirmou-se que as adicções podem ser consideradas também doenças sociocoletivas, ou seja, um reflexo direto das realidades culturais, econômicas e políticas nas quais o sujeito está inserido.

No caso da adicção dos participantes deste estudo ao crack, a família exerceu um papel preponderante nas suas histórias de vida, principalmente aquelas com uma estrutura frágil, em que tanto o pai quanto a mãe tinham dificuldades para assumir as suas funções parentais, fato observado também nas pesquisas desenvolvidas por Luz e Berni (2010). Esse aspecto fomentou a criação dos filhos com uma fragilidade socioemocional explícita, dificultando, assim, o desenvolvimento integral e a solução assertiva de conflitos. 
O exercício de educar é uma prática complexa que deve ser exercida pelos pais, os quais não podem se evadir dessa responsabilidade, salvo exceções, como limitações para o cuidado, falecimento, entre outros. Envolve aspectos que compõem uma fina sintonia entre aquilo que deve ser permitido para incentivar a liberdade individual e aquilo que deve ser reprimido ou punido para facilitar a 'engrenagem inclusiva' dos filhos na vida social. Em algumas famílias deste estudo, as crianças e, posteriormente, os adolescentes não respeitaram as regras familiares porque estas não foram impostas pelos pais ou porque não foram esclarecidas. Há de se refletir ainda como as regras são aprendidas, como são apreendidas e como são ensinadas às crianças. É importante problematizar que muitas vezes essas regras são impostas pelos pais e entendidas de uma outra forma, por isso as afirmações superficiais são complexas para se tornarem lineares. A fala abaixo reconhece a importância das normativas intrafamiliares e o desejo que demonstravam algum dos atuais moradores de rua de vivenciar um sistema de normas claras durante a infância e a adolescência:

Eu era minha própria dona, mas eu queria apoio, queria conversar com alguém, queria regras, queria uma família amorosa, queria um lar [...] nunca soube o que era um 'lar doce lar', porque o meu estava feito de fel [...]. (Moradora de rua 8 ).

As ausências acarretaram a inexistência do ensino de limites e a falta de comunicação entre os membros da família, em que as conversas com seus pais e filhos eram vazias e esporádicas. Além desses aspectos, evidenciou-se que os participantes, quando crianças/adolescentes, tinham dificuldades para lidar com a falta de amor, desinteresse e frustração que eram sentidos ao perceber essa ausência parental. Destaca-se um relato que mostra estas vivências:
Tudo parecia não ter sentido [...] Eu não tive uma verdadeira família, sou um filho do mundo, foi ele quem me criou, a minha mãe e meus pais nunca me deram nada, eu aprendi tudo sozinho, nunca tive nada [...] aprendi a me defender desde muito cedo, por culpa deles foi que cheguei a conhecer as drogas e a morte: o crack. (Morador de rua 9).

Destaca-se ainda que as relações com os pais (homens), na maioria dos casos, foram distantes; essa realidade pode ser abordada sob uma perspectiva multicausal. Uma das possíveis causas está relacionada com a situação laboral, visto que a maioria deles trabalhava durante o dia e à noite, 'não tendo' tempo disponível para dialogar, educar e participar ativamente dos momentos de crescimento dos seus filhos. Outra causa poderia estar associada ao processo do patriarcalismo no qual a própria sociedade brasileira está inserida, que dita que os homens não devem demonstrar seus sentimentos, sofrendo de uma certa punição no imaginário social aquele que apresenta demonstrações de afeto. Ainda existe outra possibilidade que pode justificar esse comportamento que diz respeito a os pais reproduzirem a forma como foram criados, portanto, haveria necessidade de se estudar por que eles criam os filhos desta forma, sob o princípio da singularidade. Talvez por esse motivo, as figuras paternas passaram a ser homens passivos que mantiveram uma distância entre eles e os seus filhos, como pode ser constatado no seguinte depoimento:

A relação com meu pai sempre foi afastada, porque ele trabalhava o dia inteiro, praticamente o dia e a noite toda [...] Daí nós não tínhamos muito tempo com ele, porque meu pai saía às cinco horas da manhã e voltava as dez horas da noite, as vezes chegava em casa as vezes não [...] então pouco ele falava com a gente. (Morador de rua 10).

Esse depoimento retrata um espaço familiar no qual o pai do entrevistado adotou um 
modelo de vida que trazia consigo a ausência como parceira cotidiana, as mensagens estavam preenchidas de vazios simbólicos, a comunicação era pouca ou nula e quando existia, lançavam-se sinais carregados de ambiguidades, assim como corroborado pela pesquisa desenvolvida por Freitas (2002). Um exemplo desse tipo de situação evidenciou-se na infância e na adolescência, quando as crianças escutavam 'discursos perversos' em que os pais puniam o consumo de drogas, mas ao mesmo tempo eles testemunhavam seus pais consumindo qualquer tipo de droga dentro de casa.

Eu lembro que meu pai sempre fumava muito e bebia bastante [...] ele sempre falava: hoje vou tomar um porre até cair. E lembro que a minha mãe também bebia bastante, quando ela bebia era de encher a cara, bebia pra caramba, na verdade a minha família toda bebia e fumava [...] Era engraçado porque quando meu pai bebia ele falava: Filho, você nunca deve beber, o que eu faço é horrível, mas ao mesmo tempo quando tinha uns 15 anos e chegava 'chapado' era ele quem sempre enchia meu copo de cachaça para bebermos juntos. (Morador de rua 11).

Essa fala desvela uma dupla mensagem do pai, na qual ao mesmo tempo que incentivou o consumo de drogas a partir de seu comportamento, também estimulou o filho a não as usar. A partir disso, possivelmente, desenvolveu uma confusão no imaginário da criança, pois, se por um lado repreendeu o uso da droga, por outro, promoveu-se o consumo por meio do exemplo. Esses discursos ambíguos e perversos contribuíram para levar o sujeito a entrar em um conflito psíquico interno. Uma das estratégias para lidar com o sofrimento que o sujeito buscou foi a utilização de drogas ilícitas, como o crack.

Assim, a existência de poucos recursos saudáveis, de uma família pouco organizada, com vínculos comprometidos e a partir de outras variáveis não pesquisadas neste artigo propuseram que os sujeitos adotassem as ruas como lar, na busca de uma liberdade simbólica.

\section{A violência como parte do cotidiano familiar}

Percebeu-se, ainda, que um dos motivos que levou os participantes a morarem nas ruas esteve relacionado com as vivências de atos de violência intrafamiliar. Esta refere-se principalmente àquela ocorrida dentro do lar e entre pessoas que vivenciam relações familiares e afetivas conflitivas.

É conhecido que a gravidade da violência doméstica é incontestável, sendo um fenômeno complexo, polêmico, expressivo, multicausal, motivo de múltiplos debates e contradições. Pode ser, em algumas ocasiões, explícita e óbvia, como nos conflitos em que a raiva chega a tomar conta dos corpos, levando à agressão física. Em outros casos, pode ser tão sutil que se encontra velada em palavras ou silêncios, dificultando, deste modo, a capacidade para identificá-la e reconhecê-la (IILVA; MANDÚ, 2012).

Sendo a violência um processo tão complexo e emaranhado, é preciso compreender a definição conceitual como um macroconceito associado ao poder e ao propósito de submeter-controlar o outro, e necessário vislumbrar o ingresso dos corpos em uma zona de desequilíbrio-movimento de poderes, sejam estes poderes reais ou simbólicos, nascidos do imaginário coletivo de papéis - paimãe, pai-filho, irmão-irmã, homem-mulher - que recriam cenários de relações assimétricas, marcadas pela desigualdade, instabilidade e subordinação (CARAVACA ET AL., 2014).

No Brasil, assim como em outros países da América Latina, a violência é um fenômeno endêmico tanto na sua etiologia quanto nas suas manifestações, pois não discrimina sexo, raça ou religião (CARAVACA ET AL., 2014).

Ao longo do tempo, as práticas de violência intrafamiliar têm transcorrido em um silêncio que, paulatinamente, estendeu sobre elas 
um manto de naturalidade. Por assim dizer, as agressões são por vezes interiorizadas e aceitas como 'atos normais', que produzem um círculo vicioso: inicialmente, 'aceita-se' a agressão e, posteriormente, reproduz-se por meio de golpes físicos/emocionais, predispondo então à agressividade sublimada $\mathrm{e}$ reprimida no autoritarismo das relações internas do eu contra o entorno (MARINHO, 2005).

Encontraram-se diversas classificações e definições contemporâneas de violência, como a visão de Galtung (2003), na qual ela é um conjunto de caraterísticas que não permitem a satisfação das necessidades concretas. Nessa concepção, a violência é vista como um iceberg, em que a parte visível é menor do que a região invisível. Esse autor classifica a violência em três tipos: violência direta, estrutural e cultural. Não obstante, adotou-se para termos deste estudo a classificação realizada por Minayo (2006) por melhor adequar-se às falas dos sujeitos. A autora segmenta a violência em quatro possibilidades: punitiva/física, sexual, psicológica e negligência/abandono; todas caraterizadas por serem práticas transgressoras de direitos e liberdades proclamadas.

A violência punitiva/física é caraterizada pelo uso da força física contra qualquer pessoa, produzindo desde uma leve dor até danos capazes de causar a morte, como evidencia o depoimento seguinte:

Lembro que eu sempre levei 'pau' dos meus pais, quase sempre quando eles estavam bêbados. Via o meu pai batendo na minha mãe até ela sangrar ou ficar roxa. Ele batia com o punho fechado, ou com um ferro que tinha no quintal [...] Achava isso muito injusto e lembro que uma vez eu me meti no meio deles e meu pai levantou aquele ferro e desceu com tudo na minha cabeça. Fiquei jogado no chão não sei quanto tempo e depois disso não lembro de muita coisa [...] Pensei que eu tivesse morrido. (Morador de rua 12).

As lembranças da infância e da adolescência dos participantes pesquisados retratam a gravidade dos golpes físicos dos quais foram vítimas. Contudo, Buvinic, Morrison e Shifter (2000), no seu estudo sobre a violência nas Américas, mencionam que existe uma aceitação da violência como um padrão cultural, no qual a punição física é tolerada e faz parte do processo de criação dos filhos, sendo interiorizada e entendida pelos sujeitos que participam do ciclo como uma das variadas ferramentas educativas:

Eu desde pequena sempre fui uma criança meio revoltada, meio nervosa, por exemplo, meu irmão sempre foi mais conformado, eu não, eu sempre fui mais de perguntar, chata mesmo, era das crianças que não se conformavam de receber um não como resposta, e queria saber o porquê [...] Queria discutir, e por isso sofri uma repressão quando eu era pequena, eu nunca vi meu irmão apanhando dos meus pais, e para mim já era diário, sabe? [...] Sempre apanhei, principalmente do meu pai, mas nada que eu não merecesse, eu acho que eu fui uma criança muito fútil, todas as surras, todas as brigas que eu tive nenhuma foi em vão, todas eu merecia, talvez não com a forma que eles me batiam, porque eram com coisas bem pesadas, do tipo borrachas, roseiras com espinhas, fios elétricos, cordas, coisas que talvez uma criança não merecesse, talvez nem um adulto merecesse passar por uma coisa desse tipo, mas todos os motivos das brigas eram coisas que eu procurava, então [...] eu não guardo magoa deles por isso. (Morador de rua 13).

Por outro lado, no contexto da violência sexual, segundo Minayo (2006) e Ferriani et al. (2008), esta é das mais traumáticas experiências que incluem desde 'carícias diferentes', toques constrangedores, até chegar aos delitos de obrigar uma pessoa a ter um contato sexual-coital, como foi exposto por um dos participantes desta pesquisa:

Quando eu tinha 8 anos, estava deitada e meu irmão estava no mesmo quarto que eu, e eu estava dormindo e eu acordei com meu irmão me tocando de um jeito diferente, não era um toque 
de carinho, de amor, era um toque diferente bem mais sexual, eu não tinha conhecimento sobre isso, e depois de tudo, eu tirei a mão dele, depois abracei meu irmão, e a gente acabou conversando porque eu pensei que ele estava demonstrando apenas um pouco de amor por mim, porque eu gostava bastante dele! É meu irmão, por mais que ele não me desse nunca atenção eu amava meu irmão. Eu tinha na figura dele um exemplo, nem sei porque [...] A partir daquele momento eu vi que meu irmão olhava para mim de outra forma, aí ele começou a me tocar... alguns outros dias eu estava dormindo e também começou a me tocar, passar a mão em mim, tirar a camisa [...] [silêncio], e acabou me abusando várias vezes sem meu consentimento [...] Só que isso continuou acontecendo mais algumas vezes até eu ter 15 anos que bati nele porque eu sentia muito nojo dele e nojo de mim [...] nunca contei para ninguém porque ele dizia que se eu contasse para alguém ele iria me matar. (Moradora de rua 15).

Nesse contexto, na maior parte dessas situações, não existe uma denúncia concreta desse ato devido, principalmente, ao temor e à manipulação que o agressor impõe sobre a vítima. Esses temores impossibilitam a denúncia porque as vítimas acreditam que ao narrar o ocorrido para algum familiar, estes poderão não acreditar. Em outras situações, esses delitos, ao serem relatados e denunciados, são velados e omitidos pelo voto de silêncio homicida da família, confirmando, dessa maneira, a ausência do apoio familiar.

Embora se saiba que existam medos e inseguranças para fazer a denúncia do acontecimento traumático, esta se apresenta como uma tarefa vital, já que o silêncio per si inocenta o agressor e ao mesmo tempo reforça seu 'poder' sobre a vítima. Minayo (2006) menciona que as consequências da violência sexual podem ser mais evidentes e com maiores repercussões na esfera social quando comparadas com outros tipos de violência. Entre as principais repercussões, descrevem-se: a dificuldade de aprendizagem acadêmica, as relações socioafetivas fragilizadas, além das ideações suicidas e da prostituição - todas presentes nos discursos das vítimas de estupro da pesquisa.

Com relação à violência psicológica, pode-se considerá-la como a forma mais subjetiva de todas as representações. Minayo (2006) descreve esse tipo de violência como um desprezo em que se bloqueiam os esforços de autoestima e autorrealização. São ações de apatia, silêncios e crueldade emocional entre os membros da família. A diversidade de contextos vivenciados espelha-se na amplitude de falas dos sujeitos investigados:

Nunca vou esquecer essa noite, meu pai me deu uma surra daquelas e disse que ele havia pedido para minha mãe abortar quando estava grávida de mim, só que a tansa da minha mãe nunca quis [...] ele me batia e dizia: 'Você é um lixo, você é uma bosta, você não deveria ter nascido'. Os roxos dessas batidas já foram embora, mas o que me marcou mais foram essas palavras que ainda me causam uma dor horrível. (Moradora de rua 8).

Esse relato revela a dor que a convivência com esse tipo de violência pode causar em algumas pessoas, provocando ao mesmo tempo demolições nas estruturas emocionais, tais como o autoconceito, a autoestima e a autopercepção. Além do mais, esse tipo de violência é uma manifestação das relações de poder historicamente desiguais e androcêntricas entre homens, mulheres, crianças, idosos e os outros membros da família.

O último tipo de violência refere-se, segundo Minayo (2006), à negligência/abandono, sendo esta definida como a ausência de cuidados e atenções físicas, emocionais e sociais, caracterizadas pela omissão, desinteresse, falta de amor, falta de atenção e ausência parental. A descrição seguinte ilustra como foi vivenciada esta experiência:

Minha mãe nunca deu muita bola para mim [...] Ela tentava me evitar, ela preferia ficar com homens do que falar com a gente [...] Nunca 
rolou de conversar com ela, nunca rolou um abraço, um 'eu te amo' nada disso. Ela não procurava a gente [...] meu pai também não procurava a gente, ele ficava o tempo todo bêbado ou fora de casa, ele não se importava nem com a gente e muito menos com os manés que minha mãe levava para casa. (Morador de rua 1).

O discurso anterior destaca o papel passivo que os pais tiveram, pois a violência surgiu como produto da omissão de atos de cuidado e de atenção. Segundo Minayo (2006), esse tipo de violência tem sido culturalmente abrandado e passa a fazer parte dos padrões sociais, criando uma falsa ilusão de não causar danos à vítima.

Aqui, a finalidade da apropriação da temática da violência sob uma perspectiva fatorial-sistêmica contribuiu na identificação das fortes repercussões que têm as dinâmicas familiares na vida pessoal e na construção das características únicas da identidade dos processos de socialização. Ao observar a família sob as lentes da instabilidade e intersubjetividade, é possível compreender como alguns fatos passados repercutem no presente e nas escolhas dos moradores de um espaço urbano destinado a ser transitado, e não habitado, servos de uma pedra homicida chamada crack.

\section{Conclusão}

Quando se faz referência ao consumo de crack e à situação da moradia nas ruas, não basta visualizar somente os dados epidemiológicos e as repercussões que este fenômeno representa - é fundamental compreender os porquês implícitos nessa situação. Faz-se necessário explorar também as explicações, motivações, propósitos e causas presentes nas histórias de vida que abrigam as justificativas para adotar a droga como refúgio e as ruas como abrigo.

Este estudo possibilitou conhecer e compreender as relações familiares na perspectiva dos moradores de rua, desvelando-se, em suas falas, uma diversidade de sentimentos direcionados ao consumo de crack enquanto construção multifatorial e processo influenciado pela falta de dedicação dos pais à educação dos filhos - por falta de tempo ou excesso de trabalho -, violência intrafamiliar ou desigualdade de gênero-poder, na qual as relações familiares fragilizadas, o álcool e o consumo de outras drogas se tornaram fatores mediadores para a ocorrência desse fenômeno.

Adota-se o entendimento de que a família é o núcleo fundamental da sociedade que gera mais influências na formação inicial da personalidade de um indivíduo e colabora com o processo de socialização primária, proporcionando ferramentas para enfrentar a vida adulta.

Ressalta-se, ainda, que depositar toda a responsabilidade na família, pela conduta dos seus indivíduos, é um erro, pois além da influência que esta tem no desenvolvimento e socialização da criança, outras condições influenciam na inicialização no consumo das drogas, como fatores econômicos, sociais, culturais e macropolíticos.

Por outra parte, é necessário executar ações para que os moradores de rua, usuários de crack, recebam um atendimento digno e de qualidade, com possibilidades de tratamento e, posteriormente, de reinserção social, já que é preciso criar oportunidades. Contudo, para a consolidação desse passo, deve-se aumentar o orçamento de recursos destinados às políticas sociais pelas diversas instâncias governamentais.

Finalmente, a multifatoriedade da dependência ao crack e da moradia na rua, assim como a busca de soluções, devem ser aplicadas com um olhar interdisciplinar às diversas dimensões envolvidas: pessoal, física, psicológica, social, econômica, familiar, questões legais e de qualidade de vida. Essa abordagem interdisciplinar é imprescindível, contudo, faz-se necessário contar com uma rede integrada de atenção psicossocial que trabalhe com ações preventivas de sensibilização e capacitação dos profissionais de saúde e educação e com 
estratégias de psicoeducação que visem reduzir os fatores de risco e promovam os fatores de proteção.

A principal limitação deste estudo tem que ver com a dificuldade de acesso para interagir com uma população maior e com igual número de participantes de ambos os sexos, assim como a dificuldade relacionada à realização de mais encontros e entrevistas devido principalmente ao estilo de vida nômade e itinerante que caracterizou os participantes.

\section{Referências}

ALARCÃO, M. (Des)equilíbrios familiares: uma visão sistemática. 3. ed. Coimbra: Quarteto Editora; 2006. (Coleção Psicologia Clínica e Psiquiatra).

BARDIN, L. Análise de conteúdo. Lisboa: Edições 70, 2011.

BUENO, M. E. N. et al. Paternidade na adolescência: a família como rede social de apoio. Texto contexto- enferm., Florianópolis, v. 21, n. 2, p. 313-319, 2012.

BURSZTYN, M. (Org.). No meio da rua: nômades excluídos e viradores. Rio de Janeiro: Garamond, 2000.

BUVINIC, M.; MORRISON, A. R.; SHIFTER, M. Violência nas América: um plano de ação. In: MORRISON, A. R.; BIEHL, M. L. (Ed.). A família ameaçada: violência doméstica nas Américas. Rio de Janeiro: FGV, 2000.

CARAVACA-MORERA, J. A. et al. Violência de gênero: um olhar histórico. História da Enfermagem, Florianópolis, v. 5, n. 1, jan./jul. 2014.

CASSELL, E. The nature of suffering. 2. ed. Oxford: Oxford University Press, 2003.

ELSEN, I.; MARCON, S. S.; SILVA, M. R. S. O viver em família e sua interface com a saúde e a doença. Maringá: EDUEM, 2002.

FERRIANI, M. G. C. et al. Debaixo do mesmo teto: análise sobre a violência doméstica. Goiânia: AB Editora, 2008.

FREITAS, L. A. P. Adolescência, família e drogas: a função paterna e a questão dos limites. Rio de Janeiro: Muad, 2002.

GALTUNG, J. Tras la violencia: reconstrucción, reconciliación, resolución: afrontando los efectos visibles e invisibles de la guerra y la violencia. Madrid: Bakeaz, 2003.

KALINA, E. et al. Drogadição Hoje. São Paulo. Ed Artes Médicas Sul, 1999.

LUZ, A. M. H.; BERNI, N. I. O. Processo da paternidade na adolescência. Rev. bras. enferm., Brasília, DF, v. 63, n. 1, p. 43-50, 2010.

MARINHO, M. B. O demônio nos "paraísos artificiais": considerações sobre as políticas de comunicação para a saúde relacionadas ao consumo de drogas. Interface (Botucatu), Botucatu, v. 9, n. 17, p. 343-354, 2005.

MINAYO, M. C. S. Violência e saúde. Rio de Janeiro: Editora Fiocruz, 2006.

SOARES, C. B. et al. Juventude e consumo de drogas: oficinas de instrumentalização de trabalhadores de instituições sociais, na perspectiva da saúde coletiva. Interface (Botucatu), Botucatu, v. 13, n. 28, p. 189-199, 2009.

SILVA, A. M. N.; MANDU, E. N. T. Abordagem de necessidades de saúde no encontro assistencial de trabalhadores e usuários na saúde da família. Texto contexto- enferm., Florianópolis, v. 21, n. 4, p. 739-747, dez. 2012.

\footnotetext{
Recebido para publicação em agosto de 2014

Versão final em março de 2015

Conflito de interesses: inexistente

Suporte financeiro: não houve
} 